\title{
Healthier streets: how superblocks and congestion pricing can help reduce air pollution in Washington, DC
}

\section{Bernat Navarro-Serer}

Department of Pathology, the Sol Goldman Pancreatic Cancer Research Center, Johns Hopkins University School of Medicine, Baltimore, MD

https://doi.org/10.38126/JSPG180110

Corresponding author: bnavarr1@jh.edu

Keywords: air pollution; urban policy; superblocks; congestion pricing

Executive Summary: Cities face big challenges, including environmental threats, livability concerns, lack of new infrastructure, and increasing social inequity, among others. These challenges call for new and innovative ways to address them. Air pollution, a common problem in many cities, causes between 100,000 and 340,000 Americans to die prematurely every year (Fann et al. 2012; Caiazzo et al. 2013; Bowe et al. 2019; and Goodkind et al. 2019) and, out of those premature deaths, 53,000 are due to car pollution (Caiazzo et al. 2013). The Washington DC Metro Area is one of the top 20 cities in the United States with the highest smog pollution, highlighting the need for new regulations to reduce air pollution (American Lung Association 2020). Federal policies aimed at lowering the maximum concentration of air pollutants allowed by the EPA could improve public health, but cities can also reduce air pollution levels through policymaking. DC currently has two main transportation and sustainability plans to improve public transportation, infrastructure, and combat climate change. Cities similar to DC, such as Barcelona and London, have applied superblocks, restricted car access city areas, and congestion pricing policies respectively, aimed at reducing air pollution and improving quality of life. Fortunately, DC has many of the characteristics needed to successfully implement superblocks in areas of the city where residential housing and businesses share space, and congestion pricing in highly congested areas. I recommend the District Department of Transportation to establish pilot programs for each of these policies to reduce air pollution levels in the city.

\section{Background}

With $69 \%$ of the residents using their cars every day (Figure 1) (District Department of Transportation 2014), the Washington DC Metropolitan Area is one of the twenty most ozone or smog polluted areas in the country, according to the State of the Air report of 2020 (American Lung Association 2020). Air pollution emitted from cars and other vehicles, which include ozone, particulate matter, and nitrogen oxides, among others, lead to overall poor air quality, which is associated with shorter average life expectancies. In 2005, 150 people died prematurely due to vehicle pollution in DC, while the estimated number of premature deaths more than triples within the DC Metro Area (Caiazzo et al. 2013). While some of these studies have been published in the past 10 years, many of them rely on data from many years ago, suggesting the need to systematically collect these data to get a better understanding of the number of premature deaths in the city due to air pollution. Importantly, Washington DC, has added 100,000 people over the last two decades to the total city population (District Department of Transportation 2014), with almost 85,000 more active vehicle registrations in the last 10 years (Department of Motor Vehicles 2019).

Current projections estimate DC will grow to 800,000 people by 2040 and will accommodate up to a million jobs (District Department of Transportation 2014). 
This is estimated to significantly increase the number of daily driving trips made to, from, and through DC, to almost $1,500,000$ vehicle daily trips by 2040 (District Department of Transportation 2014). Washington DC is already the fifth most congested city in America (Inrix 2020). This increase, with existing infrastructure, will likely increase congestion, thereby reducing vehicle speed and increasing air pollution because of longer travel times.

\section{Current policies and goals}

To face upcoming challenges, the DC Department of Transportation has developed a long-range transportation plan, moveDC, which establishes goals and policies for the city to address its future needs (District Department of Transportation 2014). moveDC is being updated this year to focus on six main goal areas: safety, mobility, management and operations, project delivery, sustainability, and enjoyable spaces (District Department of Transportation 2020). Many of the potential policies highlighted in the plan can be instituted to decrease air pollution in the city, including: (1) integrating and expanding the bicycle and pedestrian network, (2) maximizing bus reliability, and (3) ensuring safe, efficient and equitable sidewalk and curb use. Additionally, the DC Department of Energy and Environment developed Sustainable DC in 2011, a long-term policy plan that started with public events and with the collection of the residents' policy ideas regarding what a sustainable DC would look like. The plan was also supported with a series of legislative pieces aimed at supporting sustainability in the District, including the Clean Energy DC Act of 2018 and the Waste Modernization Amendment Act of 2014. In 2019, DC updated its Sustainable DC plan and prioritized goals such as (1) increasing use of public transit to $50 \%$ of all commuter trips in the city, (2) increasing biking and walking to $25 \%$ of all trips, (3) reducing commuter trips made by car to $25 \%$, and (4) reducing greenhouse gas emissions from transportation by $60 \%$, all by 2032 (Department of Energy and Environment 2019).

Both moveDC and Sustainable DC are aimed at providing more reliable public transportation and expanding non-vehicle options for residents. However, moveDC acknowledges that infrastructure alone may not be enough to reach a $75 \%$ non-auto mode share (percentage of commuters not using a private vehicle), one of its main goals (District Department of Transportation 2014). Thus, to achieve the goals highlighted in both plans, ambitious projects and policies are needed. A potential policy that could dramatically decrease traffic, promote the use of public transportation, and reduce air pollution in DC is the creation of superblocks: areas of a city with reduced traffic and increased pedestrian mobility in the interior. Superblocks completely reconceptualize streets and are aimed at eliminating car access all across a city while incentivizing other forms of transportation and producing a new space where local businesses can thrive. Congestion pricing is another prospective policy to reduce air pollution it would establish a general fee for driving in the congested areas of DC during peak rush-hours. Both of these strategies have been implemented in metropolitan cities in the European Union but have not been widely implemented in America.

\section{Policy recommendations}

i. Recommendation 1: Establish a pilot superblock in a DC mixed-use zone

Superblocks are a feasible and low-cost policy which provides an opportunity for car-free areas for everyone, independent of wealth and class. A superblock is a designated area of urban land that comprises multiple, typically sized city blocks with reduced traffic and increased pedestrian and bike mobility. The interior of the superblock is restricted to all non-emergency vehicles, with occasional exceptions for residential access, and street parking is replaced by underground parking lots (Mehdipanah et al. 2019). Vehicles move along the perimeter of the superblock, reserving the interior space mainly for pedestrians and bicycles (Figure 2). This model prioritizes pedestrians and bicycles and allows streets to provide other functions besides vehicle displacement (Mueller et al. 2020). Importantly, a study showed superblocks could lead to a reduction in the private vehicle share in Barcelona city by of almost $20 \%$, which would lower air pollution and help prevent premature deaths (Mueller et al. 2020).

DC is an excellent candidate for superblocks - a grid system and strong public transportation are essential requirements for successful superblocks, and the moveDC plan for the city aims to strengthen public transportation and non-auto options. The city also 
has mixed-used zone areas, where certain parts of the city permit a broad range of uses, including residential housing, retail businesses, and offices. Establishing superblocks in these areas is preferable, as it is an area with constant pedestrian use. These superblocks could become centers of social activity, increasing the number of people in the area and promoting economic enterprise. Pedestrian-friendly DC areas have already made a positive impact on the choice of transportation made by residents, with many opting for alternatives to private vehicles (Figure 1), highlighting the potential acceptance of this policy and willingness of the population to change their transportation habits if more options are available. Importantly, there are many co-benefits of implementing superblocks, several of which overlap with the long-term goals of moveDC, including pedestrian prioritization and decreasing the likelihood of car accidents. Recently, due to the COVID-19 pandemic, there have been changes in the mobility trends in the city. In the country, as well as DC, there has been a significant increase in bike sales (Ryan 2020; Pascale 2020), highlighting how residents are finding new ways of traveling. While it is unclear whether these trends will continue afterwards, the pandemic provides an opportunity to re-imagine how we understand urban policy and to consolidate policies not prioritizing private vehicles.

There are some challenges and limitations to the implementation of superblocks in DC. Traffic around the perimeter of the superblock and longer driving routes could lead to a rise in air pollution - in fact, initial surveys from implemented superblocks show traffic around the perimeter increased 2 to $3 \%$ (Roberts 2019). While this is just a slight increase, implementation of a large number of superblocks might cause more traffic. However, superblocks may also reduce vehicle miles traveled by decreasing demand, as some drivers might be discouraged to use their private vehicle if the traveling distance increases. This decrease in demand is particularly important because of the projected increase in jobs and population within DC. Moreover, infrastructure changes may have to be implemented to make superblocks feasible including: (1) residents' ability to enter superblocks, (2) additional bus stops near the intersections of the superblocks, and (3) increased bus frequency. Additionally, American cities might not be suitable for policies limiting private vehicle use, especially when business and residential areas are segregated in many places, thus limiting the creation of superblocks to just mixed-use zones. The creation of superblocks in certain areas might make them desirable for people to live there by providing more green spaces and pedestrian areas while reducing vehicle density (Roberts 2019). Superblocks becoming attractive areas to live may promote gentrification, causing prices and rent inside the superblock to increase and pushing current residents away from their neighborhoods (Roberts 2019). Extensive superblock creation might be needed to prevent gentrification and to significantly lower air pollution and prevent premature deaths (Mueller et al. 2020).

Barcelona is implementing this policy by creating 500 superblocks around the city. To do this, the city is using funding from the European Investment Fund, a publicly owned financial institution (Wray 2020). A study estimating the impacts of superblock implementation showed that Barcelona could reduce private vehicle use by $20 \%$ and prevent almost 700 premature deaths annually, most of which are attributed to a reduction of air pollution (Mueller et al. 2020). Some cities in the United States have implemented pedestrian malls, areas where cars are not usually permitted, highlighting the possibility of a successful superblock implementation. Establishing a pilot superblock in DC could help explore the feasibility of implementing superblocks around the city and examine the public's acceptance of such a policy.

\section{i. Recommendation 2: Implementing congestion} pricing in downtown and highly congested DC areas Another potential policy to decrease air pollution is congestion pricing. Congestion pricing implements a surcharge to financially incentivize drivers away from rush hours or to use other transportation modes, thus decreasing traffic. The fee could change based on the levels of congestion at different times of the day or on the size of the vehicle that enters the designated area. The policy, additionally, would help reduce congestion and remove cars from the city.

Importantly, the money collected from congestion pricing can be used to improve non-auto alternatives for residents and to bolster public transportation. For example, revenue could be used to repair much of the public transportation infrastructure and to fully electrify buses and the subway system, moving 
towards the goal of reducing greenhouse emissions by 2032 established in Sustainable DC (Department of Energy and Environment 2019). The District Department of Transportation (DDOT) is collaborating with DC Sustainable Transportation to fund a study evaluating the possible benefits of congestion pricing in the city. This study would analyze the benefits and revenue of implementing such a policy and how its implementation can improve equity (Lamb 2019). The study, while it has not made public yet, will include an analysis on a range of potential policy approaches, such as pricing for a specific zone, major street tolling, or parking pricing.

Many DC residents oppose the idea of congestion pricing because of concerns over how it would affect low-income residents as well as how the revenue would be used (Guskin and Lazo 2019). Equity concerns can be mitigated by adding certain exemptions to congestion pricing for low-income families. Additionally, residents support changing a lane of traffic to be bus-only, a policy that is already being implemented and that could be extended across the city with the revenue collected by congestion pricing (Guskin and Lazo 2019). The revenue could cover any infrastructure cost to adopt this policy, providing an alternative to low-income individuals who might be negatively impacted by congestion pricing.

There are cities around the world that have implemented congestion pricing policies successfully, including London, Singapore, and Stockholm (Selmoune et al. 2020). London implemented its congestion pricing policy in 2003 during most weekday hours, which led to a revenue of more than $\$ 3,500,000,000$ over a decade and reduced the number of cars in the city, decreased the number of accidents, and improved air quality (Short 2019). In both London and Stockholm, public support for congestion pricing improved after its implementation, owing mostly to residents experiencing its beneficial outcomes (Santos 2004; Börjesson 2012). Other cities, such as Manchester and Edinburgh, have failed to implement this policy, highlighting the complexity of such a project. The congestion pricing proposals for these two cities included multiple cordon-schemes, complicating the policy understanding and increasing the public's uncertainty which led, in both cases, to a rejection of the proposals in a referendum (Hensher 2013). Clear and simple goals are essential for congestion pricing to succeed, as well as quantifying such goals to elicit public support (Selmoune et al. 2020). Transparency and commitment to providing feasible alternatives might help residents transition away from cars (Selmoune et al. 2020).

DDOT should implement a pilot program to explore the feasibility of a long-term congestion pricing plan for the city. The pilot program would be based on the recommendations from the DDOT and DC Sustainable Transportation study, which would specify where, when, and whom to charge, as well as evaluate legal and technical feasibility. Implementing an initial program in the city would provide firsthand experience on the impacts on air pollution, street congestion, and public acceptability of the measure.

\section{Conclusion}

To reduce air pollution in DC, I recommend that DDOT establish both superblocks and congestion pricing pilot programs. First, a pilot to implement superblocks in the city. While the implementation of these superblocks may take time, they provide a solution to reducing car density long-term without constant policy review. Superblocks would serve two important goals: to reduce vehicle miles traveled and thus air pollution and to improve the health and living quality of DC residents by increasing pedestrian and bicycle spaces. Pilot superblocks would provide information on how they could be adopted throughout the city and on their effect. Additionally, implementing congestion pricing in the city would reduce congestion, travel times, and air pollution. While the features of congestion pricing would have to be acceptable to residents, this could be implemented faster than superblocks and could provide a source of revenue to improve public transportation and other less polluting alternatives. These two policies have the potential to transform the city, reduce air pollution, and put people at the forefront of the city's policies.

\section{Appendix}




\section{Mode of Travel to Work}

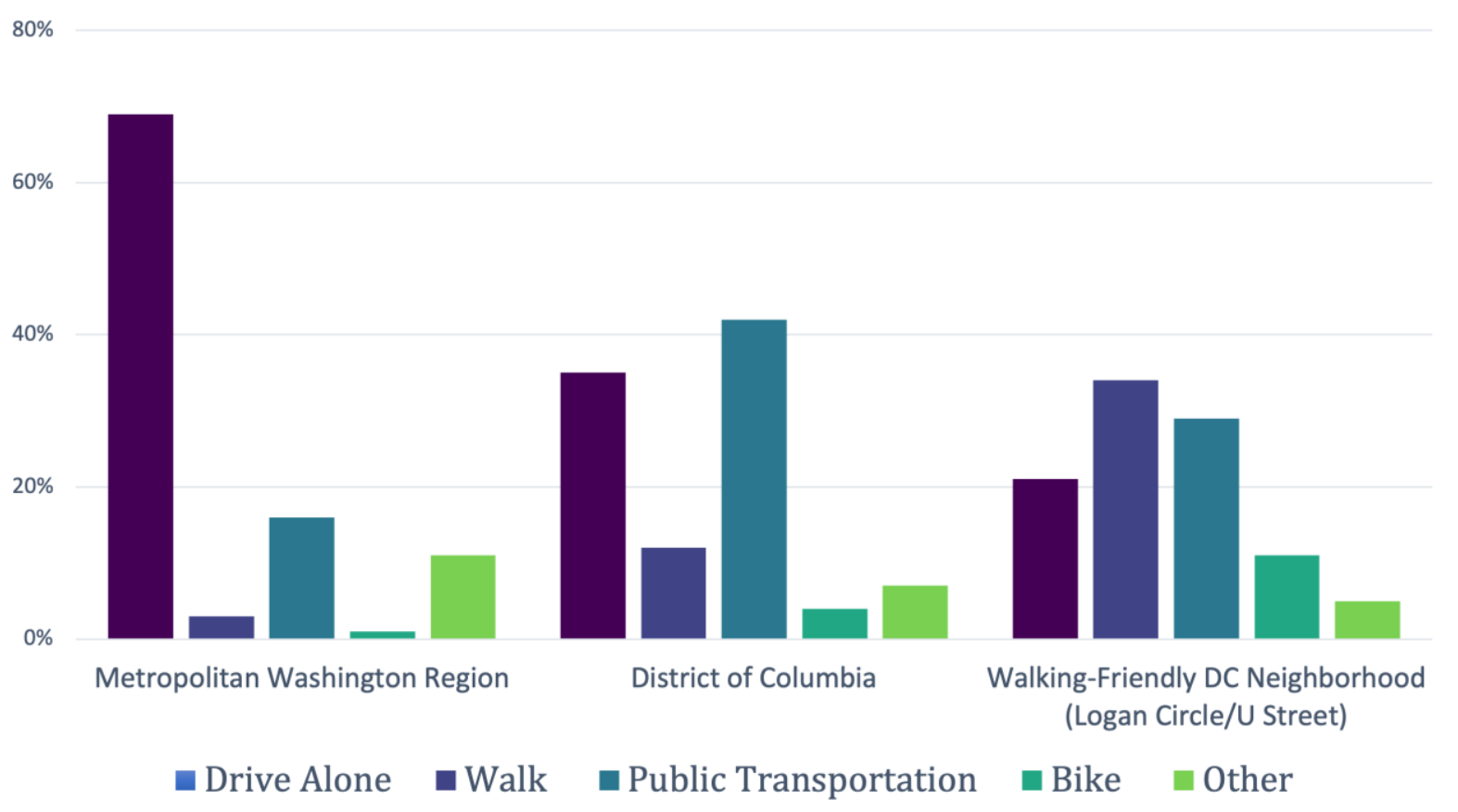

Figure 1. Percentage of commuters in the DC Metro Region, DC, and a walk-friendly neighborhood that drive, walk, or take public transportation to work. Data from moveDC, American Community Survey, MWCOG. 


\section{SUPERBLOCKS MODEL}

\section{Current Model}

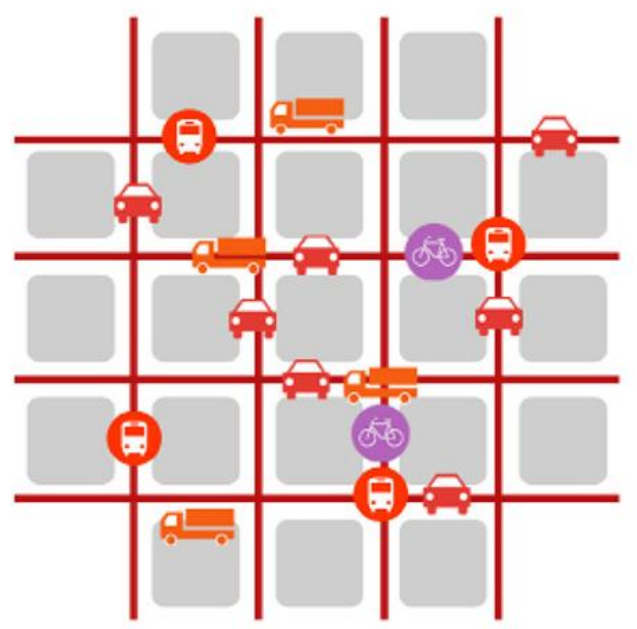

Superblocks Model

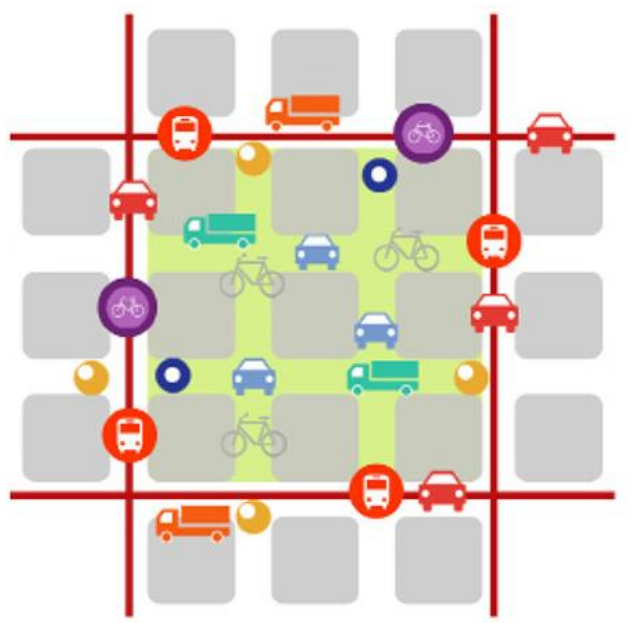

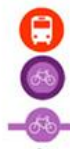

PUBLIC TRANSPORT NETWORK BICYCLES MAIN NETWORK (BIKE LANE) BICYCLES SIGNPOSTS (REVERSE DIRECTION) FREE PASSAGE OF BICYCLES

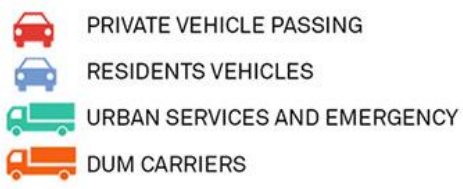

DUM PROXIMITY AREA ACCESS CONTROL BASIC TRAFFIC NETWORK SINGLE PLATFORM (PEDESTRIANS PRIORITY)

Figure 2. Current and superblock model, which provides an area within the superblock that prioritizes pedestrians and bicycles and allows certain vehicles to enter. Figure from Mobility Urban Plan, Ajuntament de Barcelona.

\section{References}

Börjesson, Maria, Jonas Eliasson, Muriel B. Hugosson, and Karin Brundell-Freij. "The Stockholm congestion charges-5 years on. Effects, acceptability and lessons learnt." Transport Policy $20 \quad$ (2012): 1-12. https://doi.org/10.1016/j.tranpol.2011.11.001

Bowe, Benjamin, Yan Xie, Yan Yan, and Ziyad Al-Aly. "Burden of cause-specific mortality associated with PM2. 5 air pollution in the United States." JAMA network open 2, no. 11 (2019): e1915834-e1915834.

https://doi.org/10.1001/jamanetworkopen.20 19.15834

Caiazzo, Fabio, Akshay Ashok, Ian A. Waitz, Steve HL Yim, and Steven RH Barrett. "Air pollution and early deaths in the United States. Part I: Quantifying the impact of major sectors in 2005." Atmospheric Environment 79 (2013): 198-208. https://doi.org/10.1016/j.atmosenv.2013.05.0 $\underline{81}$
District Department of Transportation. "Draft Policy List." moveDC, October 2, 2020. https://movedcdcgis.hub.arcgis.com/datasets/f3e0233a741a4 ef6aa64194fe8342886

District Department of Transportation. "The District of Columbia's Multimodal Long-Range Transportation Plan." moveDC, October 2014. https://movedcdcgis.hub.arcgis.com/datasets/185fc8aebe694 ab4ac24068cf5212c30

Department of Energy and Environment. "Sustainable DC 2.0 Plan Online." Sustainable DC, April 23, 2019. https://sustainable.dc.gov/sdc2.

Department of Motor Vehicles. Vehicle Registration Historical Data. Department of Motor Vehicles, 2019. $\quad$ https://dmv.dc.gov/page/vehicleregistration-historical-data. 
Fann, Neal, Amy D. Lamson, Susan C. Anenberg, Karen Wesson, David Risley, and Bryan J. Hubbell. "Estimating the national public health burden associated with exposure to ambient PM2. 5 and ozone." Risk Analysis: An International Journal 32, no. 1 (2012): 81-95. https://doi.org/10.1111/j.15396924.2011.01630.x

Goodkind, Andrew L., Christopher W. Tessum, Jay S. Coggins, Jason D. Hill, and Julian D. Marshall. "Fine-scale damage estimates of particulate matter air pollution reveal opportunities for location-specific mitigation of emissions." Proceedings of the National Academy of Sciences 116, no. 18 (2019): 8775-8780. https://doi.org/10.1073/pnas.1816102116

Guskin, Emily, and Luz Lazo. "Poll: Washington-Area Residents Widely Oppose Paying a Toll to Drive into Downtown D.C." The Washington Post. WP Company, May 2019. https://www.washingtonpost.com/local/traffi candcommuting/poll-washington-arearesidents-widely-oppose-paying-a-toll-todrive-into-downtowndc/2019/05/16/24db6dba-7284-11e9-9eb40828f5389013 story.html

Hensher, David A., and Zheng Li. "Referendum voting in road pricing reform: A review of the evidence." Transport Policy 25 (2013): 186-197. https://doi.org/10.1016/j.tranpol.2012.11.012

INRIX. "Congestion Costs Each American Nearly 100 Hours, \$1,400 A Year." Inrix, March 9, 2020. https://inrix.com/press-releases/2019-trafficscorecard-us/

Key Findings: State of the Air." American Lung Association, 2020. http://www.stateoftheair.org/keyfindings/

Lamb, Eleanor. "District of Columbia Council Proposes Congestion Pricing Study." Transport Topics, May 13, 2019. https://www.ttnews.com/articles/districtcolumbia-council-proposes-congestionpricing-study

Mehdipanah, Roshanak, Ana M. Novoa, Brenda Biaani León-Gómez, Maria José López, Laia Palència, Hugo Vasquez, Èlia Díez, Carme Borrell, and Katherine Pérez. "Effects of Superblocks on health and health inequities: a proposed evaluation framework." J Epidemiol Community Health 73, no. 7 (2019): 585-588. Harvard https://doi.org/10.1136/jech-2018-211738
Mueller, Natalie, David Rojas-Rueda, Haneen Khreis, Marta Cirach, David Andrés, Joan Ballester, Xavier Bartoll et al. "Changing the urban design of cities for health: The superblock model." Environment international 134 (2020): 105132.

Harvard https://doi.org/10.1016/i.envint.2019.105132

Roberts, David. "Barcelona Is Pushing out Cars and Putting in Superblocks. Here Are the 2 Biggest Challenges Ahead." Vox. Vox, April 10, 2019. https://www.vox.com/energy-andenvironment/2019/4/10/18273895/trafficbarcelona-superblocks-gentrification.

Ryan, Kate. "Bike Boom Continues as DC Area Moves toward Reopening." WTOP, June 11, 2020. https://wtop.com/lifestyle/2020/06/bikeboom-continues-as-areas-move-towardsreopening/.

Pascale, Jordan. "DC Bike Sales Are On The Rise During The Pandemic." WAMU. WAMU 88.5 - American University Radio, August 20, 2020. https://wamu.org/story/20/08/20/dc-bikeboom-sales-increase-covid19-pandemic/.

Santos, Georgina. "11. Urban Road Pricing In The UK'." Research in Transportation Economics 9, no. 1 (2004): 251-282. https://doi.org/10.1016/S07398859(04)09011-0

Selmoune, Aya, Qixiu Cheng, Lumeng Wang, and Zhiyuan Liu. "Influencing Factors in Congestion Pricing Acceptability: A Literature Review." Journal of Advanced Transportation. Hindawi, January 13, 2020. https://www.hindawi.com/journals/jat/2020 /4242964/ https://doi.org/10.1155/2020/4242964

Short, John Rennie. "Should U.S. Cities Use Congestion Pricing To Ease Traffic?" Smithsonian.com. Smithsonian Institution, February 8, 2018. https://www.smithsonianmag.com/innovation /should-us-cities-use-congestion-pricing-toease-traffic-180968107/

"Washington-Baltimore-Arlington Metro Area Continues to Rank Among Worst 25 in Nation for Ozone Smog, But Improved or Matched Best for All Three Measures Tracked, Finds 2020 'State of the Air' Report." Press Releases | American Lung Association, n.d. https://www.lung.org/media/pressreleases/state-of-the-air-dc.

Wray, Sarah. "Barcelona's Superblocks Get a Boost with EU Bank Finance." Cities Today - Connecting the world's urban leaders, August 5, 2020. https://cities-today.com/barcelonassuperblocks-get-a-boost-with-eu-bankfinance/. 
Bernat Navarro-Serer is a fourth-year Ph.D. Candidate studying pancreatic cancer at The Johns Hopkins University School of Medicine. He studies mechanisms of invasion in pancreatic ductal adenocarcinoma using 3D organoid models from human derived tumors. He is the Vice President at the Johns Hopkins Science Policy Group and the former Eastern Hub Co-Chair at the National Science Policy Network.

\section{Acknowledgements}

I would like to thank the SciPol Scholars Program at the National Science Policy Network for the support in helping me pitch and develop this policy memo. 